\title{
Densities of Five Selected Optical Glasses*
}

\author{
Charles T. Collett
}

\begin{abstract}
Densities of five optical glasses were determined by the hydrostatic weighing method.
Values are presented by type of glass, index of refraction, and Abbe value.
\end{abstract}

Each sample of glass used in these measurements was in the form of a cylindrical disk $30 \mathrm{~mm}$ in diameter and $5 \mathrm{~mm}$ thick. The observed densities of the samples were derived from their masses, determined by weighing in air, and their volumes, determined by hydrostatic weighing, with corrections for buoyancy.

For the hydrostatic weighing, a basket was suspended from the left pan of the balance by a wire that passed down through a hole in the case into a cabinet insulated against changes in temperature and air currents. The immersing liquid was distilled water in a Dewar flask closed by a stopper, through which holes of small diameter admitted the suspension wire, a glass stirring rod, and a platinum resistance thermometer. A galvanometer and Mueller-type resistance bridge continuously indicated the resistance of the thermometer, from which the water temperature was calculated.

The effect of surface tension was reduced as much as possible by the use of gold-plated platinum wire of small diameter $(0.20 \mathrm{~mm})$ at the region of intersection with the water surface. The errors caused by surface tension were further reduced by cancellation between the two steps of the weighing process next described.

A constant load remained on the right pan of the balance, and the immersed basket was at all times suspended from the left pan. The first step was to place each glass on the left pan with weights, $W_{1}$, sufficient to produce equilibrium. For the second step, the sample was transferred to the basket, and equilibrium was restored by increasing the weights on the pan to the value $W_{2}$.

Provided that $W_{1}$ and $W_{2}$ were determined while no change of density occurred in the water or air, the volume of the glass sample, $V_{s}$, was given by the equation

$$
V_{s}=\frac{\left(W_{2}-W_{1}\right)\left(1-\begin{array}{c}
\rho_{a} \\
8.4
\end{array}\right)}{\rho_{w}-\rho_{a}},
$$

*The companion papers in this issue present values of the index of refraction, spectral transmissive properties, and coefficients of linear thermal expansion for five different types of optical glasses produced by the Optical Glass Section of the National Bureau of Standards. These measurements have been made of the National Bureau of Standards. These measurements have been made
in the different organizational parts of the Bureau appropriate to each type of in the different organizational parts of the Bureau appropriate to each type of measurement, and are, therefore, presented separately. For each type of glass
the samples have been taken from the same melt, and, therefore, these papers the samples have been taken from the same melt, and, therefore, these
present, collectively, a consistent set of data for the five glasses studied. where $\rho_{a}$ and $\rho_{w}$ represents the densities in grams per milliliter of air and water and 8.4 the density of the brass weights. The air density was determined by means of a special buoyancy balance. ${ }^{1}$

Weights were observed to $0.1 \mathrm{mg}$, and temperatures to $0.001 \mathrm{deg} \mathrm{C}$. The observed values of density are shown in table 1.

Table 1. Densities of some optical glasses, at $23^{\circ} \mathrm{C}$

\begin{tabular}{|c|c|c|c|}
\hline \multirow{2}{*}{ Glass a } & \multirow{2}{*}{$\begin{array}{l}\text { Observed } \\
\text { densities }\end{array}$} & \multicolumn{2}{|c|}{$\begin{array}{l}\text { Densities computed } \\
\text { from factors after- }\end{array}$} \\
\hline & & $\begin{array}{l}\text { Winkelmann } \\
\text { and Schott } b\end{array}$ & Russ c \\
\hline $\begin{array}{r}\text { BSC, } n=1.517, \nu=64.5 \\
\text { LBC, } n=1.574, \nu=57.7 \\
\text { F., } n=1.620, \nu=36.2 \\
\text { DF }, n=1.649, \nu=33.8 \\
\text { Rare earth, } n=1.673, \nu=56.2\end{array}$ & $\begin{array}{l}\mathrm{g} / \mathrm{cm}^{3} \\
\text { 2. } 510_{1} \\
\text { 3. } 191_{3} \\
3.609_{5} \\
3.865_{4} \\
\text { 3. } 7866_{7}\end{array}$ & $\begin{array}{l}\mathrm{g} / \mathrm{cm}^{3} \\
2.33 \\
3.11 \\
3.59 \\
3.85 \\
\text { (d) }\end{array}$ & $\begin{array}{c}\mathrm{g} / \mathrm{cm}^{3} \\
2.44 \\
3.18 \\
3.66 \\
3.90 \\
\text { (d) }\end{array}$ \\
\hline
\end{tabular}

a $n$ is the index of refraction for the sodium $D$ line, and $\nu$, the Abbe value, equals $(n-1) /\left(n_{F}-n_{C}\right)$, where $n_{F}$ and $n_{C}$ are refractive indices for the hydrogen $F$ and $C$ lines, respectively.

b From Winkelmann and Schott's factors for oxides in glass (see footnote 2),

e From Russ' factors for oxides in glass (see footnote 2).

d No factors were given for rare-earth oxides.

Winkelmann and Schott, and Russ, ${ }^{2}$ among others, made density determinations on selected glasses and derived factors for various component oxides. By use of these factors, the density of the glass could be roughly computed.

The last two columns in table 1 give density values thus computed. The differences between these and the observed values vary from less than 0.5 percent to more than 7 percent. This is not surprising, in view of Hovestadt's ${ }^{3}$ comparisons of 29 glasses, where trial density computations based on these factors revealed differences as large as 10 percent.

1 N. S. Osborne, E. C. McKelvy, and H. W. Bearce, Bul. BS 9,327 (1913) S197 (see p. 378).

${ }^{2}$ Geo. W. Morey, The properties of glass, p. 223 (Rheinhold Publishing Corp. New York, N. Y., 1938).

${ }_{3}^{3}$ H. Hovestadt, Jena glass and its scientific and industrial applications, p. 148 (Macmillan \& Co., Ltd., London, 1902).

Washington, August 14, 1953. 